\title{
Simplified assessment of central auditory processing in individuals presented with trisomy 21
}

\author{
Daviany Oliveira Lima ${ }^{1}$ \\ https://orcid.org/0000-0003-3230-8790 \\ Marine Raquel Diniz da Rosa ${ }^{1}$ \\ https://orcid.org/0000-0003-0920-2234 \\ Ana Karina Lima Buriti ${ }^{1}$ \\ https://orcid.org/0000-0001-9504-9795 \\ Marllon dos Santos Moura e Silva ${ }^{1}$ \\ https://orcid.org/0000-0002-0184-2184 \\ Amanda Camâra Miranda ${ }^{1}$ \\ https://orcid.org/0000-0002-2616-5204 \\ Isabelle Cahino Delgado ${ }^{1}$ \\ https://orcid.org/0000-0002-0800-559X \\ Aline Menezes Guedes Dias de Araújo' \\ https://orcid.org/0000-0002-0578-599X
}

Universidade Federal da Paraíba - UFPB, Programa Associado de Pós Graduação em Fonoaudiologia - Universidade Federal da Paraíba/Universidade Federal do Rio Grande do Norte, João Pessoa, Paraíba, Brasil.

Conflict of interests: Nonexistent

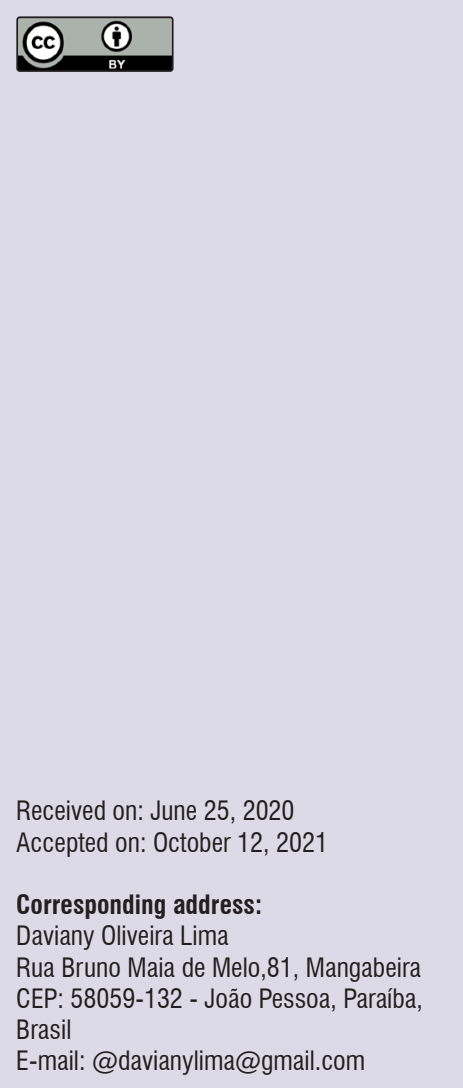

\section{ABSTRACT}

Purpose: to analyze the performance of individuals with trisomy 21 (T21) in the simplified assessment of central auditory processing, identify the impaired skills, and compare it with the results of the hearing self-perception questionnaire administered to the parents.

Methods: a descriptive, observational, quantitative study conducted at the SpeechLanguage-Hearing Teaching Clinic of a public university. The sample comprised 16 individuals with T21, aged 8 to 33 years. Simplified assessment tests of central auditory processing were conducted, namely, sounds localization and sequential memory for verbal and nonverbal sounds, diotically. Then, the Scale of Auditory Behaviors (SAB) was administered to the subjects' parents/guardians. The descriptive statistical analysis with the chi-square test considered $p<0.05$.

Results: in the simplified assessment, $81.3 \%$ had abnormal results in the memory tests for verbal sounds; $75 \%$, in the memory tests for nonverbal sounds; and $37.5 \%$, in the sound localization test. In the Scale of Auditory Behaviors, $62.5 \%$ of the answers indicated changes in the central auditory processing, demonstrating that the scale can be useful to identify such changes. However, there was no significant association between the questionnaire and the behavioral test results.

Conclusion: the results point to impaired sequential memory skills for verbal and nonverbal sounds in most individuals assessed. The simplified assessment results indicate the need for assessments of central auditory processing. Hence, the simplified assessment is highly important to detect possible changes in the central auditory processing that might interfere with the communication and overall learning of individuals presented with trisomy 21.

Descriptors: Auditory Perception; Screening; Down's Syndrome; Audiology; Hearing 


\section{INTRODUCTION}

Trisomy 21 (T21) is marked by the presence of chromosome 21, which determines the phenotypic characteristics of the disease. The incidence of T21 is approximately 1 in 700 live births ${ }^{1}$. It is characterized by microbrachycephaly, up-slanted palpebral fissure, flattened occipital, short neck, epicanthal folds, broad nasal bridge, microtia, low-implanted ears, narrow external auditory pathways, macroglossia, and microdontia.

People with T21 have significant health problems, including cognitive delays, heart diseases, gastrointestinal disorders, autoimmune dysfunction, hypothyroidism, leukemia, and hearing problems ${ }^{2}$. They also have significant changes in the frontal and temporal lobes, affecting their spatial orientation, language, speech, and social interaction ${ }^{3}$.

Another change they present with is the increased prevalence of peripheral hearing loss, especially the conductive one, due to the frequent episodes of recurrent otitis media ${ }^{4}$ in children with T21. It can be associated with ossicular chain malformation, Eustachian tube anatomical changes, or retention of cerumen secondary to the external acoustic meatus ${ }^{5,6}$.

Such a hearing loss may be either intermittent or not and cause intermittent hearing deprivation in the critical period of language development ${ }^{7}$. This can compromise the maturation of the auditory pathways, impairing the central auditory skills and, consequently, the learning process ${ }^{5-8}$.

Studies on the auditory pathway in this population and on procedures to screen possible changes in their central auditory processing (CAP) are still incipient. In this context, the simplified assessment of CAP (ASPA, as abbreviated in Portuguese) uses instruments to assess sound localization and temporal ordering skills (sequential memory for verbal and nonverbal sounds). It is low-cost, easy to access, quick to perform, and requires simple instruments (bells, sleigh bells, agogo bells, speech, and so forth). It can be considered a predictor sensitive to changes in the CAP9.

A recent review study demonstrated the scarcity of screening methods aimed at assessing the central auditory skills, emphasizing the importance of associating the use of questionnaires combined with specific auditory tasks ${ }^{9}$.

In this regard, the main guidelines have suggested using self-perception questionnaires, also known as checklists, in hearing screening of possible changes in the auditory processing ${ }^{10,11}$.
A tool that complements the ASPA is the Scale of Auditory Behaviors (SAB), which is a questionnaire capable of identifying the auditory behavior of children based on the parents' and/or teachers' perceptions. The SAB score results contribute to the ASPA, and it can help speech-language-hearing therapists, educators, and other health professionals effectively participate in the ASPA, making early diagnosis and interventions possible ${ }^{12}$.

Hence, it is utterly important to identify and investigate central auditory pathway dysfunctions in these subjects. Given the above, this study aimed to analyze the performance of people with T21 in the ASPA, identifying the impaired skills, and comparing it with the results of the hearing self-perception questionnaire administered to the parents.

\section{METHODS}

The study was approved by the Human Research Ethics Committee of the Universidade Federal da Paraíba (Federal University of Paraíba), Brazil, under number 1.302.829, in compliance with Resolution 466/12 of the National Health Council (CNS, in Portuguese). All volunteers who agreed to participate in the research signed the informed consent form.

This was a descriptive, observational, quantitative study, initially recruiting 29 volunteers with T21 who participated in a public outreach program on literacy (speech-language-hearing intervention focused on language rather than auditory training). However, 16 subjects were included in the sample because not all of them met the eligibility criteria, which were as follows: being at least 6 years old; understanding simple commands (observed in a speech-languagehearing assessment with questions on expressive and receptive language); and not having changes in the middle ear (type A tympanogram) or recent history of otitis media (in the last 6 months). The volunteers were 8 to 33 years old, six of them males and 10 , females, and they attended regular schools.

Firstly, they were submitted to meatoscopy and acoustic immittance to ensure the subject's inclusion in the study. The meatoscopy was performed to observe the external acoustic meatus. If there were obstructions, they were referred for otorhinolaryngological assessment. The acoustic immittance was performed to investigate the conditions of the middle ear, verifying the tympanic membrane complacency. The tympanogram was considered type $A$ when the maximum admittance peak was around the air pressure of 0 
daPa, whose variation did not exceed $-100 \mathrm{daPa}$; type $B$, when there was no maximum admittance peak in any air pressure; type $\mathrm{C}$, when the maximum admittance peak was displaced to negative pressures, below -100 daPA; type As, when there was a low admittance; and type Ad, when the interval between the two branches of the curve was equal to or higher than $100 \mathrm{daPa}^{13}$. It also investigated the presence of contralateral and ipsilateral acoustic reflexes at 500,1000,2000, and $4000 \mathrm{~Hz}$ (contralaterally) and 1000 and $2000 \mathrm{~Hz}$ (ipsilaterally) ${ }^{13}$, using an acoustic-immittance meter manufactured by Interacoustics, model AT 235, with test tone at $226 \mathrm{~Hz}$.

The ASPA was performed with the sound localization test (SLT) and sequential memory test for verbal (SMTV) and nonverbal sounds (SMTNV), diotically, in a sound booth at a Teaching Clinic. The volunteer sat comfortably, while one examiner played the instruments behind them and the other one took notes of their responses.

The SLT assesses sound localization skills and binaural interaction. The test was applied by presenting the sound of the sleigh bells in five directions in relation to the head (above, in front, behind, on the right, and on the left), $20 \mathrm{~cm}$ apart from one another. The criteria for normal responses were getting four or five directions right, as long as the right and left ones were correctly identified. The SMTNV assesses the auditory memory skill for nonverbal sounds, and it was applied playing four sound instruments (sleigh bells, agogo bells, bells, and/or coconut shells), in different orders. The SMTV assesses the auditory memory skill for verbal sounds, and it was applied with the oral repetition of four syllables: "pa", "ta", "ca", and/or "fa", in four orders, as all volunteers were older than 6 years. The pass criterion in the SMTV and SMTNV required the person to get two sound sequences right out of the three presented to them. The subject was said to have passed the ASPA when they responded as expected in the three tests applied ${ }^{14}$. Nonetheless, considering T21 as comorbidity, this research approached the auditory skills separately for the response analysis.
After the tests, the parents/guardians were asked to answer the SAB, which has 12 questions characterizing the subject's everyday behavioral difficulties. The answers were given on a numbered scale ranging from 1.0 to 5.0 to indicate occurrence, as follows: 1.0 corresponded to very frequent; 2.0, almost always; 3.0, sometimes; 4.0, occasionally; and 5.0, never. In the end, the values were added, reaching a total score that ranged from 12 to 60 points. The results were classified and analyzed, considering mean values of 46 points indicative of typical auditory behavior; values lower than 35 points, indicative of a need for auditory processing assessment; and values lower than 30 points, suggestive of CAP disorder, requiring long-term follow-up ${ }^{2}$.

The data obtained in this study were tabulated and organized in a digital spreadsheet and later submitted to a descriptive statistical analysis with the chi-squared test to verify the association between the ASPA and SAB. The statistical analysis was performed in the SPSS software, version 20 , presenting the variable $p<0.05$.

After the assessments, the results were communicated to the literacy outreach program team, who afterward began informally stimulating the impaired auditory skills. Those who needed more specific stimulation, according to the need perceived by the speechlanguage-hearing therapists at the outreach program and based on their indication, were referred for booth auditory training at the Department of SpeechLanguage-Hearing Therapy of the Teaching Clinic.

\section{RESULTS}

The sample comprised 16 people with T21 - 69\% females and $31 \%$ males - mean age of 16 years, ranging from 8 to 33 years.

Table 1 shows the ASPA results. There were abnormal results in $81.3 \%$ of the subjects in the SMTV test, in $75 \%$ of them in the SMTNV, and in $37.5 \%$ of them in the SLT.

Table 1. Description of the behavioral test results of the simplified assessment of central auditory processing

\begin{tabular}{|c|c|c|c|c|c|}
\hline \multicolumn{6}{|c|}{ Simplified assessment of central auditory processing } \\
\hline \multirow{2}{*}{ Test } & \multicolumn{2}{|c|}{ Normal } & \multicolumn{2}{|c|}{ Abnormal } & \multirow{2}{*}{$\begin{array}{c}\text { TOTAL } \\
\mathbf{N}\end{array}$} \\
\hline & $\mathbf{N}$ & $\%$ & $\mathbf{N}$ & $\%$ & \\
\hline Sound localization & 10 & 62.5 & 6 & 37.5 & 16 \\
\hline Sequential memory for nonverbal sounds & 4 & 25 & 12 & 75.0 & 16 \\
\hline Sequential memory for verbal sounds & 3 & 18.75 & 13 & 81.25 & 16 \\
\hline
\end{tabular}


As for the SAB, $37.5 \%$ of the subjects had normal results, $18.75 \%$ had from 30 to 35 points (indicating the need for CAP assessment), and $43.75 \%$ scored less than 30 points (indicating subjects suggestive of CAP disorder) (Table 2).

Table 2. Description of the total score obtained in the Scale of Auditory Behaviors of the individuals with trisomy $21(n=16)$

\begin{tabular}{lcc}
\hline Total score in the SAB & N & $\%$ \\
\hline$\geq 46$ points & 6 & 37.5 \\
35 to 30 points & 3 & 18.75 \\
$<30$ points & 7 & 43.75 \\
Total & 16 & 100.0 \\
\hline
\end{tabular}

Caption: SAB = Scale of Auditory Behaviors

Concerning the descriptive analysis of the ASPA results in relation to the SAB results (Table 3 ), the scaled SLT showed an agreement between the two assessment methods in eight subjects $(50 \%$ of the sample) - four were normal in both methods and four, abnormal in both methods. There was also an agreement between the SMTNV and the scale in 10 subjects - two were normal in both methods, and eight, abnormal in both methods. Although the tests revealed an agreement between the assessment methods, no significant association was observed.

Table 3. Description of the results obtained in the simplified assessment of central auditory processing associated with the results in the Scale of Auditory Behaviors

\begin{tabular}{|c|c|c|c|c|c|c|}
\hline Tests & \multicolumn{5}{|c|}{ SAB Questionnaire } & \multirow{3}{*}{${ }^{*}$ p-value } \\
\hline \multirow{2}{*}{ CAP } & \multirow[t]{2}{*}{ Results } & \multicolumn{2}{|c|}{ Normal } & \multicolumn{2}{|c|}{ Abnormal } & \\
\hline & & $\mathbf{N}$ & $\%$ & $\mathbf{N}$ & $\%$ & \\
\hline \multirow{2}{*}{ SL } & Normal & 4 & 40.0 & 6 & 60.0 & \multirow{2}{*}{0.608} \\
\hline & Abnormal & 2 & 33.3 & 4 & 66.7 & \\
\hline \multirow{2}{*}{ SMTNV } & Normal & 2 & 50.0 & 2 & 50.0 & \multirow{2}{*}{0.489} \\
\hline & Abnormal & 4 & 33.3 & 8 & 66.7 & \\
\hline \multirow{2}{*}{ SMTV } & Normal & 2 & 66.7 & 1 & 33.3 & \multirow{2}{*}{0.304} \\
\hline & Abnormal & 4 & 30.8 & 9 & 69.2 & \\
\hline
\end{tabular}

*Paired chi-square test with a significant difference $(p<0.05)$.

Captions: SL-sound localization; SMTNV-sequential memory test for nonverbal sounds; SMTV- sequential memory test for nonverbal sounds; CAP-central auditory processing

\section{DISCUSSION}

According to the literature, there is a close relationship between the CAP and speech acquisition, as some auditory skills, such as temporal processing, influence the time taken to process information and speech sounds ${ }^{14}$. There are CAP changes in people with T21, with different types of impairment, which may interfere with oral and written language acquisition and development. Thus, it is important to make peripheral and central hearing assessments in this population ${ }^{10}$.

This research emphasized the use of an auditory behavior questionnaire and the ASPA in people with
T21. Most of these subjects obtained less than 46 points (Table 2), which is suggestive of CAP disorder.

Likewise, Table 1 shows abnormal results in all the ASPA tests, occurring more often in the SMTV and SMTNV. These abnormal results correspond to difficulties in the auditory skills of simple verbal and nonverbal sound ordering, which may hinder language acquisition and development ${ }^{9}$.

There was no significant association between the tests, even though they agreed (Table 3). Nevertheless, including well-structured questionnaires on auditory behavior (such as the $\mathrm{SAB}$ ) along with the $\mathrm{ASPA}^{15}$ 
may help identify CAP deficits early. It may also help develop future assessment, diagnostic, and therapeutic processes that will make it possible to minimize this population's learning difficulties and improve their communication ${ }^{16}$.

It is important to point out that children with T21 have difficulties discriminating verbal time, suggesting a basic deficit or delay in speech processing, which will probably restrict their subsequent language development ${ }^{17}$. These findings can be justified with the electrophysiological assessment, which demonstrates a cortical information processing delay. This in turn suggests a preattentional auditory processing delay in patients with T21, besides an impaired detection of the underlying auditory stimulus, as both hemispheres are compromised $^{18}$.

A neural information processing time delay may be found, suggesting an impairment in the discrimination of and attention to sound stimuli in patients with $\mathrm{T} 21^{19}$. Therefore, a low cognitive capacity may not be the only explanation of speech perception impairments ${ }^{18}$.

Hence, language development is influenced by the person's perception skills. The ASPA and the SAB demonstrate that clinicians and educators must be attentive to the hearing health of these subjects and of school-age children because it is an important step in detecting this disorder early ${ }^{19}$.

Based on this research and the population's difficulties, questionnaires should be administered to monitor hearing along with the ASPA. Using these instruments may help in initiatives to screen auditory processing at schools and in making strategies to develop auditory skills. In this sense, there is a need for more in-depth studies addressing this population in the field in question to help them in their hearing and speech performance.

This research has limitations regarding the sample number it assessed, as half the recruited population could not be included because of cognitive and middle ear issues. It must be highlighted that few studies or pieces of research addressing this population are available. Nonetheless, the results obtained may have theoretical-practical implications in the field of speechlanguage-hearing pathology concerning the importance of assessing auditory skills in people with T21 and administering auditory monitoring questionnaires. These may help guide the speech-language-hearing therapy for them to achieve better communication and learning development.

\section{CONCLUSION}

The results point to impairments in sequential memory for verbal and nonverbal sounds in most subjects assessed. As for the ASPA, its results indicate the need for CAP assessment. Hence, the ASPA is highly important to detect possible CAP changes that might interfere with the communication and overall learning of people presented with T21.

\section{REFERENCES}

1. Kanamori G, Witter M, Brown J, Williams-Smith L. Otolaryngologic manifestations of Down syndrome. Otolaryngol. Clin. N. Am. 2000;33(6):1285-92.

2. Schwartzman JS. Org. Síndrome de Down. In: Summers, apud Show RL, Seikel A. São Paulo (SP): Mackenzie: Memnon. op cit; 2003.p.217-20.

3. Malt E, Dahl R, Haugsand T. Health and disease in adults with Down syndrome. Tidsskr Nor Laegeforen. 2013;133(3):290-4.

4. Ziesel SA, Roberts JE. Otitis media in young children with. disabilities, Infants Young Child. 2003;76(4):106-19.

5. Morales-Angulo C, Gallo-Terán J, Azuara N, Quintela JR. Manifestaciones otorrinolaringológicas en el síndrome de Down. Acta Otorrinolaringol Esp. 2006;57:262-5.

6. Zúñiga J, Raggio M. Síndrome de Down en otorrinolaringología. Rev Otorrinolaringol Cir Cabeza Cuello. 2015;75(1):49-54.

7. Katz I, Wilde L. Distúrbios da percepção auditiva em crianças. In: Katz I, editor. Tratado de audiologia clínica, 3a ed. São Paulo (SP): Manole;1989. p.674-94.

8. Downs MP. Effects of mild hearing loss on auditory processing. Otolaryngologic Clinics of North America.1985;1815(1):6-16

9. Capovilla FC, Salido LFM. Avaliação simplificada do processamento auditivo: normatização e efeito de inteligência não-verbal sobre localização de fonte sonora e memória sequencial de sons verbais e não verbais: Transtorno de aprendizagem. São Paulo (SP): Memnon, 2010.

10. Doyle WJ, Webster DB. Neonatal conductive hearing loss does not compromise brainstem auditory function and structure in rhesus monkeys. Hear Res. 1991;54(3):145-51. 
11. Popescu MV, Polley DB. Monaural deprivation disrupts development of binaural selectivity in auditory midbrain and cortex. Neuron. 2010;65(5):718-31.

12. Nunes CL, Pereira LD, Carvalho GS. Scale of Auditory Behaviors e testes auditivos comportamentais para avaliação do processamento auditivo em crianças falantes do português europeu. CoDAS. 2013;25(3):209-15.

13. Russo ICP, Valente CHB, Lopes LQ, BrunettoBorginanni LM. Medidas de Imitância Acústica. In: Momensohn-Santos TM, Russo IC, editors. Prática da Audiologia Clínica. 7ạ Ed. São Paulo (SP): Cortez; 2009. p.183-216.

14. Neves IF, Schochat E. Maturação do processamento auditivo em crianças com e sem dificuldades escolares. Pró-Fono R. Atual. Cientif. 2005;17(3):311-20.

15. Souza IMP, Carvalho NG, Plotegher SDCB, Colella SMF, Amaral MIR. Auditory processing screening: contributions of the combined use of questionnaire and auditory tasks. Audiol Commun Res. 2018;23:2021.

16. Jerger $S$, Jerger J. Alterações auditivas: um manual para a avaliação clínica. São Paulo (SP). Atheneu; 1989.

17. Ferreira DRSA, Ferreira WA, Oliveira MS. Pensamento e linguagem em crianças com síndrome de Down: um estudo de caso da concepção das professoras. Cien. Cogn. 2010;15(2):216-27.

18. American Academy of Audiology Clinical Practice Guidelines. Diagnosis, treatment and management of children and adults with central auditory processing disorder. 2010

19. Caumo DTM, Ferreira MIDC. Relationship between phonological disorders and auditory processing. Rev Soc Bras Fonoaudiol. 2009;14(1):234-40. 